\title{
Osteoporosis - a current view of pharmacological prevention and treatment
}

This article was published in the following Dove Press journal:

Drug Design, Development and Therapy

30 May 2013

Number of times this article has been viewed

\section{Subhajit Das \\ Julie C Crockett}

Musculoskeletal Research Programme, School of Medicine and Dentistry,

University of Aberdeen, Aberdeen, UK

Correspondence: Julie C Crockett Musculoskeletal Research Programme, Division of Applied Medicine, University of Aberdeen, Room 3.16, Institute of Medical Sciences,

Foresterhill, Aberdeen AB252ZD, UK Tel +44 I 224437472

Email j.c.crockett@abdn.ac.uk
Abstract: Postmenopausal osteoporosis is the most common bone disease, associated with low bone mineral density (BMD) and pathological fractures which lead to significant morbidity. It is defined clinically by a BMD of 2.5 standard deviations or more below the young female adult mean (T-score $=-2.5$ ). Osteoporosis was a huge global problem both socially and economically - in the UK alone, in $2011 £ 6$ million per day was spent on treatment and social care of the 230,000 osteoporotic fracture patients - and therefore viable preventative and therapeutic approaches are key to managing this problem within the aging population of today. One of the main issues surrounding the potential of osteoporosis management is diagnosing patients at risk before they develop a fracture. We discuss the current and future possibilities for identifying susceptible patients, from fracture risk assessment to shape modeling and in relation to the high heritability of osteoporosis now that a plethora of genes have been associated with low BMD and osteoporotic fracture. This review highlights the current therapeutics in clinical use (including bisphosphonates, anti-RANKL [receptor activator of NF- $\mathrm{KB}$ ligand], intermittent low dose parathyroid hormone, and strontium ranelate) and some of those in development (anti-sclerostin antibodies and cathepsin K inhibitors). By highlighting the intimate relationship between the activities of bone forming (osteoblasts) and bone-resorbing (osteoclasts) cells, we include an overview and comparison of the molecular mechanisms exploited in each therapy.

Keywords: BMD, fracture, bisphosphonate, strontium, denosumab, teriparatide, raloxifene

\section{Physiological control of bone remodeling}

A healthy skeleton is maintained throughout life by the constant process of bone remodeling that is regulated by the balanced activities of bone-resorbing osteoclasts and bone-forming osteoblasts (Figure 1) to maintain normal physiological structure and mineral content. The bone remodeling process is completed in 4-6 months. It takes place mostly in a nontargeted manner to remove old bone and involves resorption of bone by peripheral blood-derived multinucleated osteoclasts, followed by bone formation by osteoblasts. ${ }^{1}$ Remodeling also takes place at specific, targeted bone surfaces, which develop stress-induced microfractures attracting osteoclasts by signaling via osteocytes embedded deep within the mineralized bone..$^{2-4}$ The activation of different bone cells in the bone remodeling process is orchestrated by multiple pathways such as receptor activator of nuclear factor (NF)- $\kappa B$ ligand (RANKL) and Wnt signaling pathways, and these pathways are exploited in the development of new therapies for osteoporosis. ${ }^{5}$ 


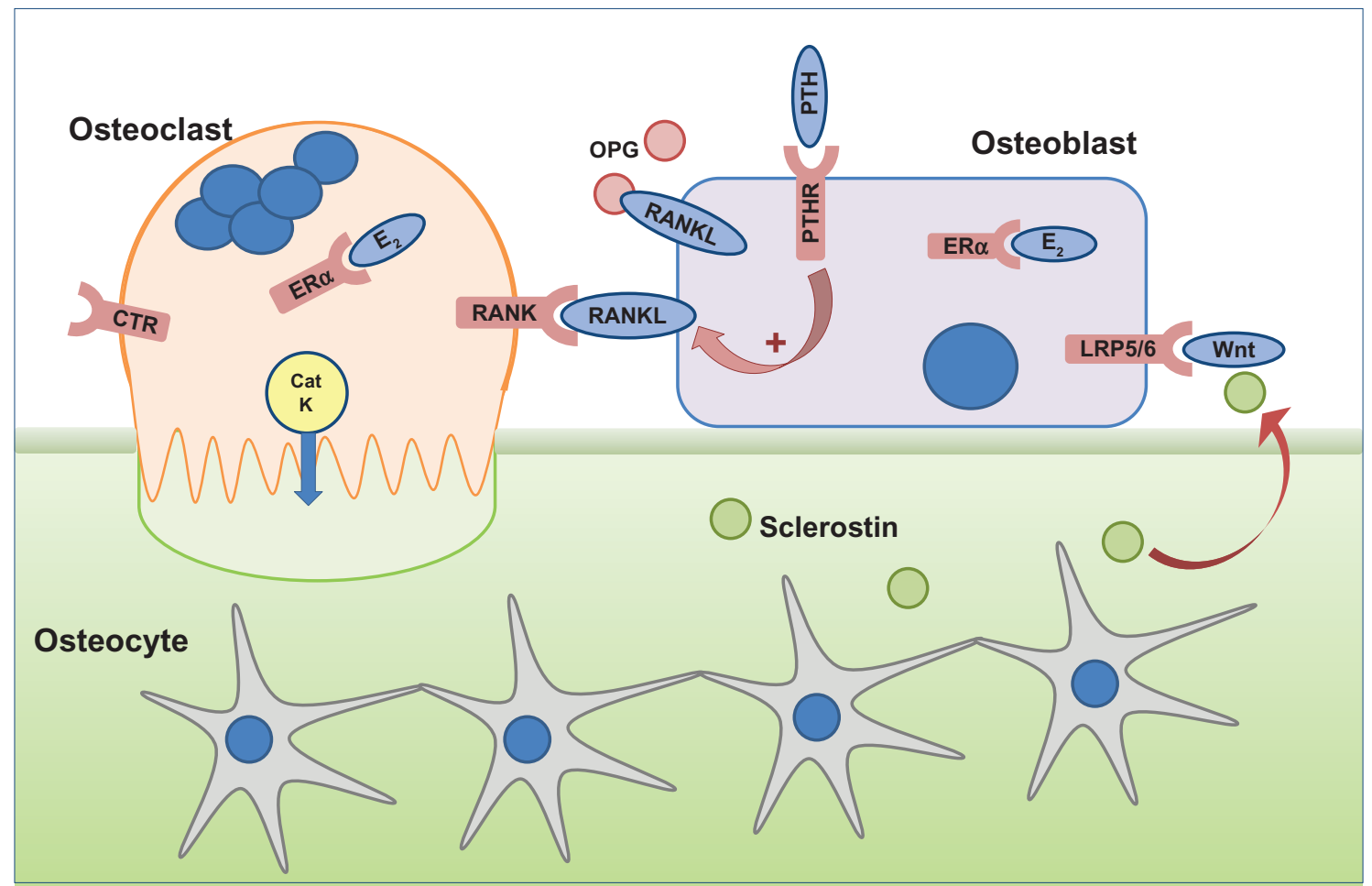

Figure I The cells responsible for bone remodeling, highlighting key signaling pathways that are targets for therapies recommended for the prevention of osteoporotic fracture.

Notes: Osteocytes are embedded within mineralized bone and, in response to mechanical loading or microdamage, provide signals to osteoclasts to resorb. Osteoclast differentiation and function is dependent on the RANKL-RANK signaling pathway, which in vivo, is negatively regulated by OPG. Circulating PTH is a physiological regulator of plasma calcium and binds to PTHR on osteoblasts to indirectly stimulate osteoclast activity via upregulation of RANKL and downregulation of OPG expression. Calcitonin binds to the CTR expressed on mature osteoclasts to reversibly inhibit osteoclast function, although the exact physiological relevance for calcitonin is not fully understood. $E_{2}$ has a positive effect on bone, through effects on osteoblasts and osteoclasts via $E R \alpha$. CatK is secreted by resorbing osteoclasts across the convoluted ruffled border membrane and is required to degrade collagen. Osteoclast activity releases factors from the bone, which attract osteoblasts to the site of resorption. Osteoblast differentiation and function is controlled by the Wnt signaling pathway via the LRP5/6 and Frizzled co-receptors, which is regulated by endogenous inhibitors such as sclerostin, expressed by osteocytes and upregulated in response to unloading.

Abbreviations: CatK, cathepsin K; CTR, calcitonin receptor; $\mathrm{E}_{2}$, estrogen; ER $\alpha$, estrogen receptor; LRP5/6, lipoprotein-related protein 5/6; OPG, osteoprotegerin; PTH, parathyroid hormone; PTHR, PTH receptor; RANK, receptor activator of nuclear factor- $\kappa B$; RANKL, RANK ligand.

\section{Osteoporosis - an exploding 2 I st century problem of an aging population}

Osteoporosis is defined by the World Health Organization as a value for bone mineral density (BMD) 2.5 standard deviations or more below the young female adult meanreferred to as a T-score of -2.5 , where a T-score of zero is equal to the young female adult mean. ${ }^{6}$ It is estimated that one in two women and one in five men over the age of 50 years in the UK (National Osteoporotic Society, UK) and an estimated 44 million Americans (National Osteoporotic Society, USA) are at risk of osteoporotic fracture - most commonly fractures of the hip, wrist, and vertebra. Therapies to inhibit osteoclasts are effective at preventing bone loss, but osteoporosis often goes undiagnosed until an individual receives a bone scan after a fracture. Population screening by dual-energy X-ray absorptiometry (DXA) bone scans (which is the current gold standard for osteoporosis diagnosis) is not cost-effective, and therefore new, reliable methods to identify individuals with low BMD are required. ${ }^{7}$ Since the treatment of osteoporotic fracture has a huge impact on individual recovery and the national health budget, this serves to highlight the pivotal role for early diagnosis, prevention, and treatment of osteoporosis.

Osteoporosis is caused by an uncoupling of bone resorption from bone formation such that the activities of osteoclasts far outweigh those of the osteoblasts. Peak bone mass is achieved in early adulthood and, following this point, both women and men lose bone with increasing age. However, this process is accelerated in postmenopausal women whereby the loss of estrogen is associated with an increase in osteoclast activity. Decades of research indicates that estrogen plays a dominant multifactorial role in maintaining cortical bone formation by supporting osteoblasts and preventing bone resorption by suppressing osteoclast formation and stimulating osteoclast apoptosis. $^{8,9}$ 
In men, testosterone plays a crucial role in protecting the skeleton. Experiments with androgen receptor knockout mouse models showed that the absence of androgen receptors on the surface of bone cells leads to the development of osteoporosis in male mice, but not in female mice. ${ }^{10}$ These experiments showed that the protective action of testosterone is mediated via the supportive activity of osteoblasts on osteoclasts, not directly on osteoclasts themselves. Although testosterone has a direct effect on bone, estrogen is also important in maintaining bone health in men since estrogen activity in bone cells is via the conversion of androgen to estrogen, indicating a dual protective action of androgens in men. ${ }^{11}$

Secondary osteoporosis is defined as osteoporosis that develops as a consequence of an unrelated underlying cause. ${ }^{12}$ These can include a drug treatment (eg, chronic corticosteroid use), hypogonadism, malnutrition or eating disorders such as anorexia nervosa, excessive exercise, and neoplastic disorders.

The integrity of the skeleton is also intricately linked to appetite and energy balance, and the underlying mechanism by which bone mass is regulated by the brain is through a leptin-mediated brain-derived serotonin pathway. ${ }^{13}$ This research indicates potential adverse effects of anti-obesity leptin therapy on bone mass and confirms the molecular basis of the bone loss that is associated with prolonged treatment with selective serotonin reuptake inhibitors. ${ }^{14}$

\section{Osteopenia - destined for osteoporosis?}

Osteopenia is diagnosed when a T-score by DXA is between -1 and $-2.5{ }^{6}$ There is no clear consensus as to whether to treat osteopenia with pharmacotherapy. Osteopenia per se is not a criterion for pharmacotherapy under current guidelines, although treatment could be initiated if other risk factors are associated, particularly in men. One study showed that the majority of fractures occurred in osteopenic women, and this put emphasis on the careful assessment of osteopenic patients with high risk factors whilst restraining from treating all osteopenic patients. ${ }^{15,16}$ It was suggested that further assessment of these patients with high resolution peripheral quantitative computed tomography (HR-pQCT) was needed.

\section{Screening methods for osteoporosis}

DXA of hip and lumbar spine is the most commonly used diagnostic tool for osteoporosis assessment. ${ }^{17}$ DXA is very expensive, and many patients only receive a scan after a fracture. Identifying individuals that are at highest risk of pathological fracture and therefore likely to benefit from preventative treatment is an important goal in osteoporosis management. This could be achieved using alternative scanning methods, since for example, HR-pQCT together with finite element analysis for bone strength has demonstrated improved fracture risk prediction than DXA measurements. ${ }^{18}$ Fracture prediction calculators, including FRAX $^{\circledR}$ (Fracture Risk Assessment), QFractureScores ${ }^{\circledR}$, and the Garvan Institute fracture calculator, are algorithm-based methods to estimate risk of fracture, considering lifestyle factors such as body mass index as well as alcohol and smoking history. ${ }^{19-21}$ Fracture risk calculators can be used as tools to determine individuals that would benefit from a DXA scan, and FRAX ${ }^{\circledR}$ and Garvan can also be used in conjunction with BMD measurements to provide a fracture prediction score. FRAX ${ }^{\circledR}$ has been validated for use in many countries; however, there is some debate about whether these risk calculators actually provide better prediction of osteoporotic fracture than assessing age and BMD alone, and the importance of calibration of the algorithms to local cohorts, time period for risk assessment, and inclusion of risk of mortality have been highlighted and discussed in detail. ${ }^{22-24}$ It is likely that other non-BMD assessments in addition to DXA are required to improve osteoporosis detection. ${ }^{25}$ Active shape and appearance modeling were developed based on previous observations that differences in femoral geometry and bone quality might increase susceptibility to hip fracture. ${ }^{26,27}$ Different studies have employed a range of statistical algorithms to assess femoral neck appearance and shape from computed tomography, X-ray, and DXA images in cross-sectional and longitudinal studies. ${ }^{28}$ A correlation was found between the texture and appearance and actual measured bone strength of femora, supporting the development of appearance models, and in recent crosssectional and prospective studies, active shape and appearance models of the hip predicted significantly more fractures than BMD measurements alone. ${ }^{28}$ Common to each study was that increased likelihood of fracture was associated with greater neck shaft angle. ${ }^{29-31}$ These results suggest that subtle shape and appearance differences between individuals could act as additional biomarkers, which could be incorporated into fracture assessment tools given appropriate adaption to allow automatic point placement.

\section{Is osteoporosis susceptibility in the genes?}

As a stepping stone to determining a genetic link in osteoporosis, twin and family studies have shown that up 
to $85 \%$ variation in $\mathrm{BMD}$ can be attributed to genes. ${ }^{32,33}$ Although initially genome-wide scans revealed no significant association to individual genes due to low sensitivity, later genome-wide association studies showed single nucleotide polymorphisms (SNPs) associated with variation in BMD, and most recently, up to 56 loci were associated with low BMD, of which 14 were associated with osteoporotic fractures. ${ }^{34-36}$ Many of these genes are associated with regulation of bone mineral homeostasis. ${ }^{37}$ As it is becoming apparent that multiple SNPs are responsible for osteoporosis, it may be possible in the near future to screen for the risk of development of osteoporosis using SNPs as biomarkers and allow monitoring and therapeutic management of genetically at-risk patients to be implemented earlier.

\section{Risk factors and prevention of bone loss or fracture}

Risk factors for developing low BMD, osteoporosis, and fracture include inherent, nonmodifiable factors as well as those that individuals can address to prevent or slow down onset of osteoporosis. Age, sex, and family history are independent risk factors for developing low BMD. Everyone loses bone mass with age, but women are at higher risk since they rapidly lose bone around and following menopause. The modifiable risk factors for developing osteoporosis have been systematically studied using observations from participants of the Framingham Heart Study, showing that low baseline weight, weight loss, and alcohol use in women, and smoking in men were associated with loss in BMD. ${ }^{38} \mathrm{~A}$ history of previous fragility fractures (vertebral or hip) is a strong predictor of future fractures, and given that falling is also a strong predictor of fracture, approaches to assessing the risk of falling together with risk of fracture is likely to be beneficial. ${ }^{39,40}$

Adequate calcium and vitamin D status are associated with good bone health, and studies that have examined the effect of a range of different vitamins and other dietary factors on maintaining BMD highlight the need for adequate and balanced nutrition. ${ }^{41-43}$

\section{Current therapeutic management options for osteoporosis}

There is a range of anti-resorptive or anabolic options for the prevention of osteoporotic fracture. The history of when each drug was approved for use for osteoporosis by the US Food and Drug Administration (FDA) or the European Medicines Agency (EMA) in the case of strontium ranelate is detailed in Figure 2. All therapeutic management strategies for the prevention and treatment of osteoporosis include recommendations for calcium and vitamin $\mathrm{D}$ supplementation.

\section{Anti-resorptive drugs Bisphosphonates}

Bisphosphonates are the most commonly used drugs for the treatment of osteoporosis. They avidly bind to bone and are internalized by osteoclasts to inhibit resorption (Figure 3). They are administered both orally and intravenously and are divided into two classes - the low potency non-nitrogen containing bisphosphonates and the potent nitrogencontaining bisphosphonates. These two classes have distinct intracellular targets and molecular mechanisms of action that lead to inhibition of osteoclast-mediated bone resorption. ${ }^{44}$

All bisphosphonates have a phosphate-carbon-phosphate backbone with two side chains $\left(\mathrm{R}_{1}\right.$ and $\left.\mathrm{R}_{2}\right)$. The non-nitrogen containing bisphosphonates have simple side chains (in etidronate $\mathrm{R}_{1}$ and $\mathrm{R}_{2}$ are $\mathrm{CH}_{3}$ groups, in clodronate $\mathrm{R}_{1}$ and $\mathrm{R}_{2}$ are $\mathrm{Cl}$ groups) and are metabolized in osteoclasts to non-hydrolysable analogs of adenosine triphosphate (ATP), accumulation of which causes osteoclast apoptosis. ${ }^{45}$ On the route to clinic, etidronate was successfully administered to

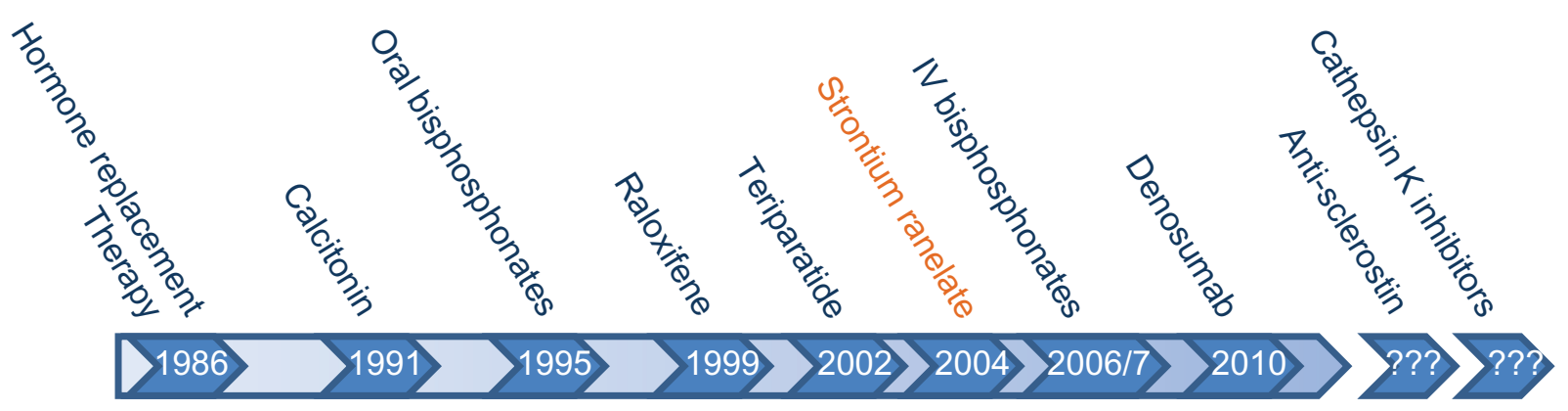

Figure 2 Key milestones in the lifecourse of osteoporosis therapy. Strontium ranelate is not approved by the FDA but all other agents have been approved both by the FDA and EMA.

Note: The dates shown represent the year that they were first approved by the FDA (or EMA for strontium ranelate) for use in the treatment of osteoporosis. Abbreviations: EMA, European Medicines Agency; FDA, US Food and Drug Administration; IV, intravenous. 


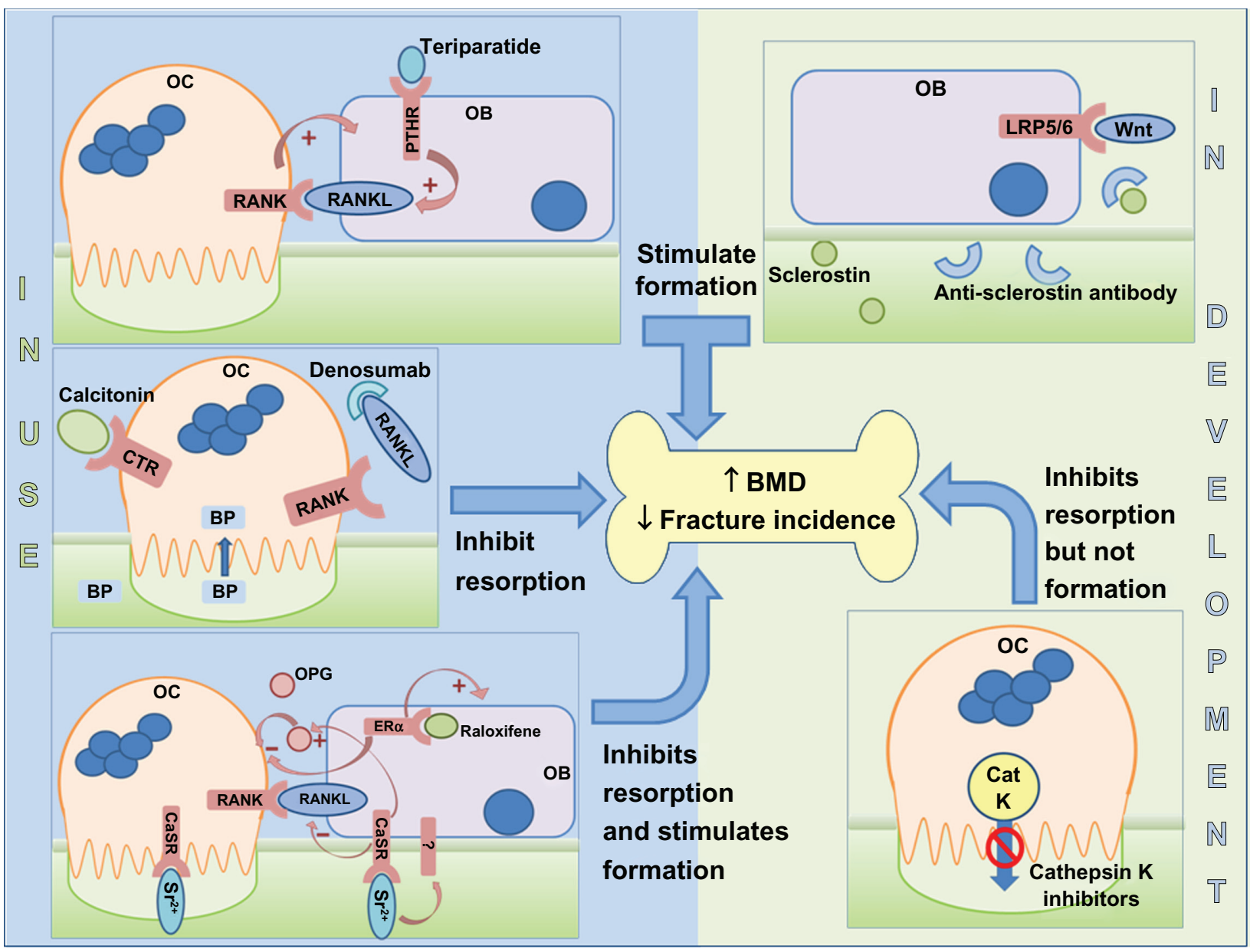

Figure 3 Sites of action of different classes of drugs that are either in clinical use (left hand side) or in development (right hand side).

Notes: Drugs that inhibit resorption: BPs are internalized and inactivate resorbing osteoclasts, whilst calcitonin binds to a cell-surface receptor to inhibit osteoclast function. Denosumab prevents RANKL interacting with RANK, therefore potentially inhibiting both the differentiation of osteoclasts and the function of mature osteoclasts. Drugs that stimulate formation: Teriparatide, an analog of PTH, binds to the PTHR on osteoblasts and, following a transient increase in osteoclast activity, a coupled increase in osteoblast activity is observed. Anti-sclerostin antibodies prevent sclerostin binding to the LRP5/6 coreceptor, thereby allowing Wnt ligands to activate the canonical signaling pathway in osteoblasts. Drugs that uncouple bone formation from resorption: Raloxifene interacts with intracellular ER $\alpha$ in osteoblasts and, via upregulation of OPG and downregulation of RANKL, inhibits osteoclasts. Raloxifene also has positive effects on osteoblast proliferation. Strontium ranelate $\left(\mathrm{Sr}^{2+}\right)$ substitutes for $\mathrm{Ca}^{2+}$ in the bone and interacts with the CaSR on osteoblasts, upregulating OPG expression and downregulating RANKL expression to indirectly inhibit osteoclasts, whilst acting directly on the CaSR on osteoclasts themselves to induce apoptosis. The anabolic effect of strontium ranelate on osteoblasts is also mediated via the CaSR as well as potentially other, unidentified receptors. Cathepsin $\mathrm{K}$ inhibitors uncouple resorption from formation since the cross-talk between inactive osteoclasts and osteoblasts is maintained.

Abbreviations: BMD, bone mineral density; BP, bisphosphonate; CaSR, calcium-sensing receptor; CatK, cathepsin K; CTR, calcitonin receptor; ER $\alpha$, estrogen receptor; LRP5/6, lipoprotein-related protein 5/6; OPG, osteoprotegerin; PTH, parathyroid hormone; PTHR, PTH receptor; RANK, receptor activator of nuclear factor-KB; RANKL, RANK ligand; OB, osteoblast; OC, osteoblast.

treat a young patient with myosytis ossificans progressive in 1968, and prior to the use of etidronate $\left(\right.$ Didrone $\left.^{\circledR}\right)$ as an anti-osteoporotic drug it was used to treat Paget's disease of bone before Procter and Gamble developed it for treatment of osteoporosis. ${ }^{46-48}$

In the nitrogen-containing bisphosphonates, $\mathrm{R}_{1}$ tends to be $-\mathrm{OH}$ and $\mathrm{R}_{2}$ contains a nitrogen molecule either attached to a multiple carbon side-chain (as in alendronate and pamidronate) or in a heterocyclic group (such as risedronate and zoledronate). These bisphosphonates are not metabolized to non-hydrolysable ATP analogs but inhibit farnesyl pyrophosphate synthase (FPPS), an enzyme in the mevalonate pathway. ${ }^{49,50}$ In addition to cholesterol biosynthesis, this pathway is responsible for synthesis of farnesyl and geranylgeranyl pyrophosphate, required for the prenylation and correct subcellular localization of proteins, including small GTPases that regulate processes critical for osteoclast function, including vesicular trafficking. ${ }^{51}$ The potency of nitrogen-containing bisphosphonates for inhibiting FPPS activity correlates with their ability to inhibit resorption in vivo. ${ }^{52,53}$

Alendronate (Fosamax ${ }^{\circledR}$; oral, $70 \mathrm{mg}$ ) is the most commonly prescribed drug for the treatment of postmenopausal osteoporosis and is associated with increased BMD 
and fracture risk reduction. ${ }^{54}$ Oral bisphosphonates but especially alendronate are associated with gastrointestinal side effects, despite detailed guidance on when and how to take the medication. Risedronate $\left(\right.$ Actonel $\left.^{\circledR}\right)$ and etidronate $\left(\right.$ Didronel $^{\circledR}$ ) are recommended for patients who are unable to tolerate alendronate. These side effects are likely one of the reasons for patient noncompliance with oral bisphosphonates. Intravenous administration of other nitrogen-containing bisphosphonates (pamidronate, zoledronate) overcomes this patient non-compliance, and a $5 \mathrm{mg}$ dose of zoledronate $\left(\right.$ Aclasta $^{\circledR}$ ) is highly effective at reducing fracture risk and preventing new fractures if administered as an annual single infusion. ${ }^{55}$ It is approved for use in women at high risk of fracture or who have experienced a previous osteoporotic fracture. Intravenous bisphosphonates are generally well tolerated, and the most commonly observed side effect is self-limiting flu-like symptoms which persist for about 3 days following the first administration, mediated by circulating monocytes and activation of specific subsets of T-cells. ${ }^{56}$ Osteonecrosis of the jaw (ONJ) is a rare but recognized side effect resulting from long-term bisphosphonate use. The estimated rates of occurrence in osteoporosis patients taking oral bisphosphonates range from $1 / 100,000$ to $1 / 10,000$ patient years of oral bisphosphonate administration. ${ }^{55,57}$ The route of administration of bisphosphonate and duration of treatment affects the projected time to onset of ONJ (median time of 3 years for intravenous and 5 years for oral) and may explain why ONJ is more common in cancer patients receiving higher doses of intravenous zoledronate than in osteoporosis patients whose first-line therapy is oral alendronate. ${ }^{58,59}$ Accumulating evidence suggests that long-term use of bisphosphonates is associated with atypical fracture of the femur, diagnosed upon presentation with a characteristic combination of features to distinguish from typical femoral fractures. ${ }^{60-62}$ Recommendations by the FDA in 2010 advised that bisphosphonate labeling be changed to raise awareness of the potential increased risk of such fractures with extended bisphosphonate use. The pathophysiologic mechanism of this unique type of fracture is likely to be related to the affinity of bisphosphonates for areas of increased bone remodeling, thus accumulating in high concentration in bone matrix. This means prolonged absence of osteoclast activity, which by virtue of the tight coupling of osteoblast to osteoclast activity will result in a subsequent inability of osteoblasts to repair microdamage. ${ }^{63}$

There have been a few reports of cases of treatment failure or incidence of fragility fracture in patients taking antiosteoporotic medications, particularly bisphosphonates. ${ }^{64}$
This group of patients was categorized as nonresponsive or resistant to bisphosphonate treatment, and it would be interesting to determine whether this nonresponsiveness was a result of genetic differences. A single nucleotide polymorphism (rs2297480) within the promoter region of FPPS was recently associated with low BMD and reduced response to bisphosphonate treatment in postmenopausal women, with carriers of the rare allele demonstrating significantly less improvement in BMD with long-term bisphosphonate treatment compared with homozygous carriers of the common allele. ${ }^{65-67}$ It was suggested that the variant allele destroys a Runx1 binding site, likely leading to increased FPPS transcription. ${ }^{44}$ We have recently found resistance to bisphosphonate treatment is induced in vitro when endogenous FPPS is upregulated. ${ }^{68}$

\section{Denosumab}

The interaction of RANKL with RANK is critical for the formation and function of bone-resorbing osteoclasts. Denosumab (Prolia ${ }^{\circledR}$ ), a fully human monoclonal antibody against RANKL, is an anti-resorptive drug that acts by preventing RANKL from interacting with RANK on the osteoclast precursor cells (Figure 3). This inhibits the differentiation and function of these cells and is associated with fracture prevention at multiple sites. ${ }^{69}$ In 2010 , denosumab (60 mg, subcutaneous injection every 6 months) was licensed by the FDA for use in postmenopausal women who are at high risk of osteoporotic fracture and for those that have been nonresponsive to other osteoporosis therapies. In 2012, it was approved for treatment of osteoporosis in men with high risk of fracture. When the effectiveness of denosumab and alendronate treatment in postmenopausal women was compared, denosumab was at least as effective at increasing BMD at the hip and lumbar spine. ${ }^{70}$ Although clinical effectiveness was maintained for up to 6 months following a single injection of denosumab, cessation of treatment was associated with a more rapid reduction in BMD compared with bisphosphonate therapy, since unlike bisphosphonates, denosumab is not incorporated into the structure of the bone itself and therefore resolution of denosumab-associated ONJ may be more rapid than bisphosphonate-induced ONJ if treatment is stopped. ${ }^{71}$

\section{Calcitonin}

Calcitonin is a naturally occurring peptide hormone synthesized and secreted by the thyroidal C-cells. The precise role for calcitonin in human physiology is not fully understood, but levels of calcitonin are elevated when serum 
calcium levels are low, and it has been proposed that calcitonin is important to regulate calcium levels during periods of physiological stress such as during lactation and pregnancy. Mature osteoclasts express calcitonin receptors and, in vitro, calcitonin acts directly on osteoclasts to inhibit resorption (Figure 3). ${ }^{72-74}$ Calcitonin is less effective for increasing BMD in postmenopausal women when compared with $10 \mathrm{mg}$ alendronate. ${ }^{75}$ Intranasal salmon calcitonin (200 IU per day) is licensed for the treatment of postmenopausal osteoporosis. However, the EMA conducted a review of calcitonin use for postmenopausal osteoporosis and recommended that calcitonin should no longer be prescribed for management of osteoporosis. This was attributed to evidence that linked calcitonin use to increased risk of cancer. ${ }^{76}$ The FDA will hold a similar review early in 2013.

\section{Anabolic agents}

\section{Teriparatide}

Parathyroid hormone (1-84; PTH) plays a central role in calcium homeostasis by maintaining the serum calcium level within the physiological range by indirectly (via osteoblasts) stimulating osteoclasts to resorb bone. ${ }^{77}$ Although in hyperparathyroidism this catabolic effect leads to loss of bone mineral content, PTH has an anabolic effect on bone remodeling when administered intermittently. ${ }^{78}$ Teriparatide (1-34 amino acid peptide) is a human PTH analog which also has an osteoanabolic effect when administered intermittently at low doses. ${ }^{79}$ Teriparatide $\left(\right.$ Forteo $\left.^{\circledR}\right)$ is effective $(20 \mu \mathrm{g} /$ day subcutaneously) at increasing BMD in postmenopausal and glucocorticoid-induced osteoporosis and is more effective than alendronate at reducing the incidence of vertebral and hip fractures. ${ }^{80-82}$ Both the pro-resorptive and anabolic functions of teriparatide are required for clinical effectiveness. Combining anti-resorptive therapy (to inhibit bone loss) with teriparatide therapy (to stimulate bone formation) has agent-specific effects on the overall effectiveness of teriparatide therapy. The administration of raloxifene prior to teriparatide improves BMD above that of teriparatide alone. ${ }^{83}$ In open-label studies, alendronate blunted the ability of teriparatide to increase BMD when the therapies were combined, ${ }^{79}$ whereas in another study patients that had been previously treated with risedronate showed better improvement in BMD in response to teriparatide than patients that had previously been on alendronate therapy. ${ }^{84}$ Randomized trials that examined the effect of combining PTH (1-84) itself with alendronate showed no synergistic effects on BMD at multiple sites. ${ }^{84}$ However, if patients that had taken PTH (1-84) for 1 year were randomized to alendronate, they showed significant improvement in BMD. ${ }^{84}$ Recently, a pilot randomized study examining the effect of concurrent or sequential administration of ibandronate with just 6 months PTH (1-84) demonstrated overall improvements in BMD but with a blunting of the anabolic effect of PTH. ${ }^{85}$ Taken together, these data demonstrate that more studies are needed to clarify the most appropriate combination therapies to best exploit the anabolic potential of intermittent PTH-based therapies.

The exact mechanism leading to the anabolic effect of teriparatide is not fully understood, but it has been shown to enhance osteoblast formation from its circulating precursors and prevent osteoblast apoptosis. ${ }^{85,86}$ Despite its anabolic effect on bone, the use of teriparatide in osteoporosis remains guarded due to the associated high incidence of osteosarcoma in animal models; however, a long-term clinical study has so far found no association between osteosarcoma and teriparatide in humans. ${ }^{87,88}$ Teriparatide is approved by the FDA as an anabolic treatment for osteoporosis in individuals at high risk of fracture. The potential to reduce the frequency of administration (and hence increase compliance) is a possibility given that a single $20 \mu \mathrm{g}$ dose of teriparatide is effective for up to 1 week. ${ }^{89}$ In addition, alternative delivery systems (such as intranasal and transdermal) are currently being tested, and an implantable wirelessly controlled drug delivery device for teriparatide is in clinical trial for postmenopausal osteoporosis..$^{90,91}$

\section{Strontium ranelate}

Divalent strontium ions have the capacity to substitute for calcium within bone without adversely affecting mineralization. ${ }^{92}$ Strontium ranelate $\left(\right.$ Protelos $^{\circledR}$ ) increases BMD and reduces the risk of vertebral and nonvertebral fractures..$^{93-95}$ The protective effect of strontium ranelate results from an uncoupling of bone formation from resorption, thereby increasing functional osteoblasts whilst simultaneously decreasing osteoclasts. ${ }^{96}$ The mechanism by which strontium has these concomitant effects is thought to involve, at least in part, the calcium sensing receptor (CaSR) (Figure 3), the receptor responsible for mediating cellular responses to extracellular calcium ions. ${ }^{97-99}$ However, there is also evidence for CaSR independent pathways. ${ }^{98,100}$

Strontium ranelate is not approved by the FDA, but is licensed (oral formulation of $2 \mathrm{~g}$ /day) for restricted use for the prevention of vertebral and nonvertebral osteoporotic fractures in the EU, in patients where bisphosphonate treatment has failed or is contraindicated. The prescribing guidelines have been amended recently to account for 
reported adverse effects of strontium ranelate treatment, including skin rashes and deep vein thrombosis. ${ }^{101}$

\section{Raloxifene}

Given the potential adverse effects of long-term hormone replacement therapy use on extra-osseous tissues, including slight increased risk of cardiovascular disorders and uterine and breast cancers which appear to be directly related to the duration of treatment, hormone replacement therapies are no longer recommended for prevention of osteoporosis. ${ }^{102,103}$

To overcome the potential unwanted tissue-specific effects of estrogen, selective estrogen receptor modulators (SERMs) were investigated for a potential role in osteoporosis management. Tamoxifen, used to treat breast cancer, also has beneficial effects on $\mathrm{BMD}$, and raloxifene hydrochloride $\left(\right.$ Evista $^{\circledR}$ ) improves BMD in postmenopausal women and was approved by the FDA for use in the prevention of osteoporosis in postmenopausal women in $1997 .{ }^{104}$ In the EVA (Evista vs Alendronate) trial, a direct comparison with daily oral alendronate $(10 \mathrm{mg})$ demonstrated that daily oral raloxifene (60 $\mathrm{mg}$ ) was equally as effective at reducing fracture risk; however, this study was terminated early because of slow enrollment, so the numbers in the final analyses were low. ${ }^{105}$ A recent retrospective database analysis found similar improvements in fracture rates in alendronate versus raloxifene-treated cohorts, with reduced risk of breast cancer in the raloxifene-treated patients. ${ }^{106}$ Side effects of raloxifene treatment include an increased risk of fatal stroke and venous thromboembolism that were observed in the RUTH trials. ${ }^{107}$ Given that raloxifene is also effective at reducing the risk of developing breast cancer, the FDA subsequently approved it in 2007 for treatment of postmenopausal women with high risk of breast cancer. ${ }^{108}$ In addition to synthetic SERMs, there is increasing interest in the therapeutic application of naturally occurring phytoestrogens in the regulation of bone remodeling and prevention of bone loss. One example is genistein, an isoflavone found in soybeans that effectively prevents postmenopausal bone loss without adverse effects on other tissues. ${ }^{109}$ However, the overall effectiveness of phytoestrogens on fracture risk has not been proven.

\section{Monitoring response to treatment}

Response to treatment with anti-resorptive or anabolic therapeutic agents is monitored by assessing the biochemical markers of bone turnover (Table 1). These allow for treatment efficacy assessment and highlight nonresponsiveness. Treatment strategies can be reviewed and amended based
Table I Serum biomarkers for osteoporosis

\begin{tabular}{ll}
\hline Osteoblastic activity markers & $\begin{array}{l}\text { Osteoclastic activity } \\
\text { markers }\end{array}$ \\
\hline $\begin{array}{l}\text { Total or bone specific alkaline } \\
\text { phosphatase }\end{array}$ & $\begin{array}{l}\text { Tartrate resistant acid } \\
\text { phosphatase (TRAP) } \\
\text { Osteocalcin }\end{array}$ \\
$\begin{array}{l}\text { C-terminal telopeptide } \\
\text { of collagen type I (ICTP) }\end{array}$ \\
$\begin{array}{l}\text { N- or C-terminal propeptide of } \\
\text { protocollagen type I }\end{array}$ \\
$\begin{array}{l}\text { N-terminal telopeptide } \\
\text { of collagen type I (NTX) }\end{array}$ \\
$\begin{array}{l}\text { Note: Adapted with permission of Elsevier. Original Source: Torres E, Mezquita P, } \\
\text { DeLa Higuera M, Fernandez D, Munoz M. Actualizacion sobre la determinacion de } \\
\text { marcadores de remodelado oseo. Endocrinol Nutr. 2003;50(6):237-243. }{ }^{133}\end{array}$
\end{tabular}

on these measurements, in accordance with local, approved guidelines. In addition, DXA scans will be performed to monitor BMD changes, but these changes can take years to detect by DXA, and a recent study suggested the use of stable isotopes of calcium for rapidly assessing changes in BMD. ${ }^{110}$

\section{Is it possible to compare the overall clinical effectiveness of different osteoporosis therapies?}

In the absence of randomized, blinded clinical trials comparing all available treatments, research groups have employed network meta-analysis approaches to compare the relative effectiveness of different bisphosphonates on vertebral fractures or the range of different classes of approved agents described in this review on hip, vertebral, and non-vertebral fracture prevention. ${ }^{111,112}$ Overall, they conclude that all agents (except etidronate) reduce the risk of vertebral and non-vertebral fractures when compared with placebo. Jansen et al ${ }^{111}$ concluded that zoledronate was more effective than other bisphosphonates at reducing vertebral fractures, and Freemantle et $\mathrm{al}^{112}$ showed that denosumab was not different to zoledronate but was more effective at reducing the occurrence of vertebral fractures than strontium ranelate, raloxifene, risedronate, and alendronate.

\section{The next generation of therapeutics for osteoporosis management? Anti-sclerostin antibodies}

Sclerostin is expressed by osteocytes, secreted as a monomer, and was first identified as the gene mutated in sclerosteosis, a disease featuring hyperostotic bones. ${ }^{113}$ Sclerostin is a negative regulator of bone formation by 
antagonizing the interaction between Wnt ligand and LRP5/6 co-receptor on osteoblasts, thus inhibiting canonical Wnt signaling. Sclerostin expression is upregulated during mechanical unloading, which is associated with reduced $\mathrm{BMD}$, and sclerostin antibodies prevent bone loss associated with unloading in mice. ${ }^{114,115}$ Phase I trials of AMG785 (a humanized monoclonal antibody against sclerostin) showed increase in bone formation and reduction in bone resorption markers in healthy men and postmenopausal women, and Phase II trials are underway (NCT00896532). ${ }^{116,117}$ AMG 167 (also a humanized monoclonal antibody against sclerostin) has completed Phase I clinical trials for the treatment of osteopenia (NCT01101048; results pending).

\section{Cathepsin $\mathrm{K}$ inhibitors}

Cathepsin K was first cloned from a human cDNA library in 1995, and expression was localized predominantly to osteoclastoma tissue. ${ }^{118,119}$ It is a lysosomal cysteine protease released by osteoclasts across the ruffled border during bone resorption and catalyses the degradation of type I collagen. Nonsense mutations in cathepsin $\mathrm{K}$ were identified in patients with pycnodysostosis, a disease characterized by nonfunctioning osteoclasts, and it was this together with the osteopetrotic phenotype of Ctsk-/- mice that confirmed cathepsin $\mathrm{K}$ as a possible therapeutic target for osteoporosis. ${ }^{120,121} \mathrm{~A}$ number of cathepsin $\mathrm{K}$ inhibitors have been developed, and most to date have been discontinued as a result of adverse reactions due to lack of selectivity or drug interactions. Odanacatib is a selective, reversible nonpeptidic biaryl inhibitor of cathepsin $\mathrm{K}$, which is effective at increasing BMD with $50 \mathrm{mg}$ weekly doses, given a relatively long half-life (up to 93 hours). ${ }^{122,123}$ Odanacatib reduces bone resorption whilst maintaining bone formation - an uncoupling of bone formation from resorption likely as a result of the fact that cathepsin $\mathrm{K}$ inhibition does not reduce osteoclast numbers and therefore osteoclast-osteoblast coupling factors (such as the ephrins) have the potential to maintain osteoblast recruitment and function. ${ }^{124}$ Odanacatib has reached Phase III clinical trials in postmenopausal women (NCT00529373 and NCT00729183). In 2012, Medivir AB (Switzerland) commenced a Phase I trial of their lead cathepsin K inhibitor MIV-711.

\section{Stem cell therapy}

Over recent years, stem cell therapy in musculoskeletal research has exploded, and there is a wide range of possible clinical applications for such technologies, many focusing on tissue repair following damage, including bone fractures, cartilage lesions, or ligament and tendon injuries. ${ }^{125}$ One hurdle in the development of therapies exploiting endogenous mesenchymal stem cells (MSCs) is their lack of capacity to home to bone surfaces. A recent study indicated the possibility of directing endogenous MSCs to the bone surface using piggyback technology in which LLPA2, the ligand for integrin $\alpha 4 \beta 1$ expressed by MSCs, is administered in vivo, piggybacked onto alendronate. When LLPA2 binds to MSCs, the bisphosphonate directs those stem cells to the bone surface where osteoblastic differentiation and subsequent bone regeneration takes place. In studies in mice, this approach was effective when employed to direct transplanted MSCs to the bone surface, and the results strongly indicated that the homing of endogenous MSCs was positively influenced too. ${ }^{126}$

\section{Treatment guidelines}

Representative treatment guidelines for postmenopausal women are summarized in Figure 4. In men, specific guidelines are not published, however the Endocrine Society suggest a guideline for pharmacological treatment of osteoporosis in men based on a T-score of -1 or below and FRAX ${ }^{\circledR}$ scoring. ${ }^{127}$ Elderly men with low serum testosterone and a risk of fracture are advised to take testosterone and a bone protective drug such as bisphosphonate or teriparatide. Any improvement in treatment can be monitored every $1-2$ years.

\section{How long should osteoporosis treatment be continued?}

As the human life span is gradually increasing, more and more elderly people are being treated for primary and secondary osteoporosis over increasing periods of time. The question arises as to whether it is necessary or clinically prudent to treat osteoporosis for many years. This is particularly relevant for bisphosphonates, which are the first choice treatment. As bisphosphonates have an apparent half-life of more than 10 years due to selective adherence to the bone surface, successive treatment over years would not only have a cumulative effect, but may actually be detrimental for bone health by preventing the cyclical changes required to maintain normal bone architecture. ${ }^{128}$ In a recent report from the FDA, it was suggested that, based on evidence from three long-term clinical trials, patients are unlikely to benefit from continued treatment with bisphosphonates beyond 3-5 years, and it was difficult to predict how long the beneficial effect of bisphosphonates would remain after discontinuation of therapy. ${ }^{129}$ One alternative is to stop bisphosphonate therapy for a "drug 


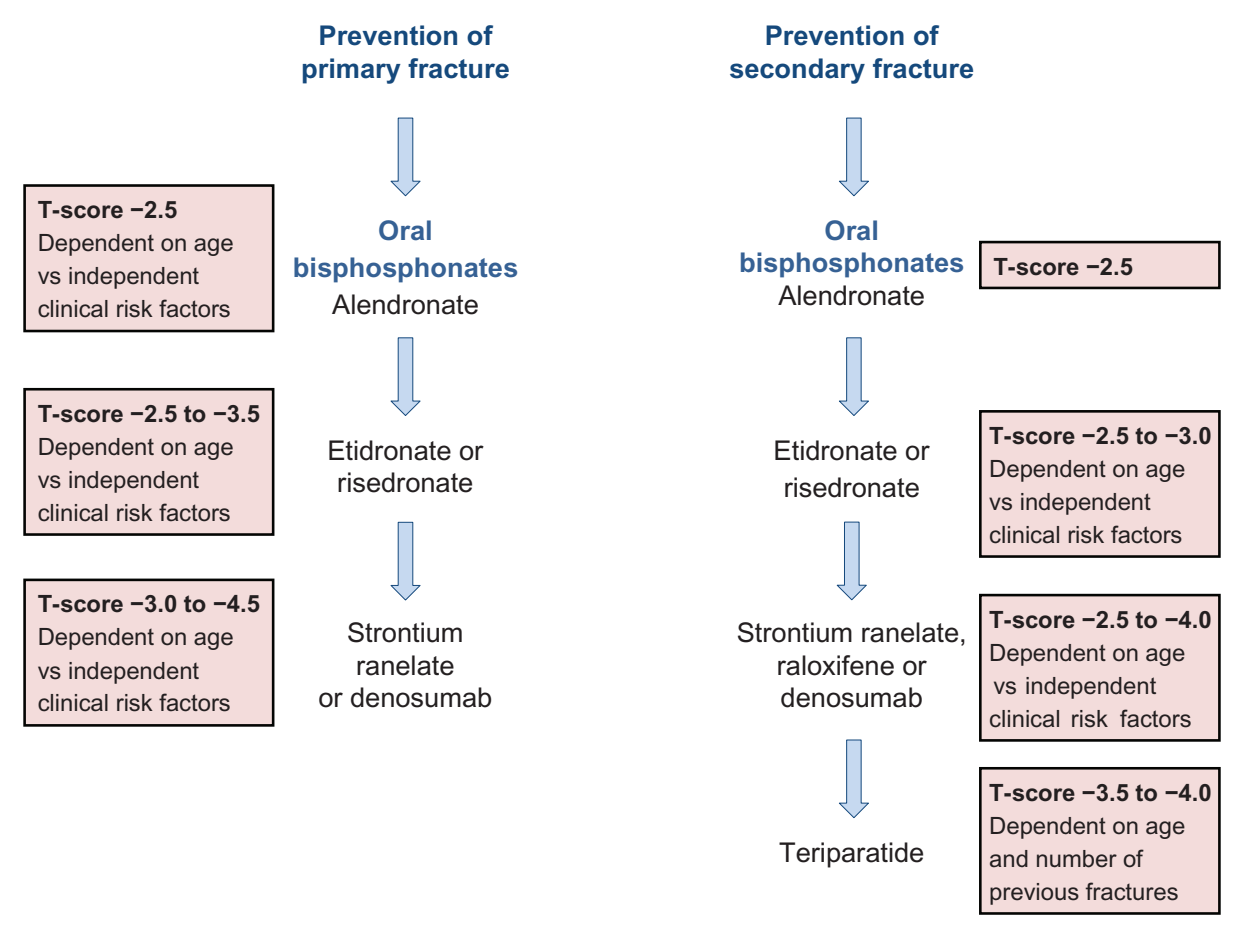

Figure 4 A summary of the National Institute for Clinical Excellence (NICE) guidelines (available at http://publications.nice.org.uk) for the therapeutic management of primary and secondary osteoporotic fractures in postmenopausal women.

Notes: Alendronate is the treatment of choice in each case, but for those intolerant or contraindicated for alendronate, a hierarchy of treatment choices is recommended and patients are assigned to each treatment based on T-score, the magnitude of which depends on age and the number of independent clinical risk factors.

holiday" to allow normal bone remodeling to resume, and then to restart therapy. ${ }^{130}$

\section{Conclusion}

Currently, bisphosphonates are the mainstay treatment for osteoporosis. Although there are concerns about their long-term effect, they are one of the safest drugs because of very short serum half-life ( $4 \mathrm{mg} / 5 \mathrm{~min}$ intravenous infusion reaching less than $1 \%$ of initial serum concentration at 24 hours postadministration) and high tissue specificity. ${ }^{131}$ Moreover, since alendronate is now off-license and therefore a generic drug, it is far cheaper compared with other available treatments for osteoporosis. As described in this review, there are a wide range of alternatives to the use of bisphosphonates, for those individuals who are unable to tolerate or are contraindicated for bisphosphonates. In addition, there are exciting new treatment options on the horizon, the development of which have followed directly from the identification of key molecules critical to the maintenance of a healthy skeleton.

\section{Acknowledgments}

SD is generously supported by a PhD studentship from Roemex Ltd, Portlethen, UK within the Nuffield Oliver Bird PhD Programme at the University of Aberdeen. JCC is supported by a New Investigator Research Grant from the Medical Research Council, UK (G10004-35).

\section{Disclosure}

SD and JCC have no affiliation with any industry with interest in the management of osteoporosis and no conflicts of interest.

\section{References}

1. Clarke B. Normal bone anatomy and physiology. Clin JAm Soc Nephrol. 2008;3 Suppl 3:S131-S139.

2. Wenzel TE, Schaffler MB, Fyhrie DP. In vivo trabecular microcracks in human vertebral bone. Bone. 1996;19(2):89-95.

3. Rumpler M, WurgerT, Roschger P, et al. Microcracks and osteoclast resorption activity in vitro. Calcif Tissue Int. 2012;90(3): 230-238.

4. Kennedy OD, Herman BC, Laudier DM, Majeska RJ, Sun HB, Schaffler MB. Activation of resorption in fatigue-loaded bone involves both apoptosis and active pro-osteoclastogenic signaling by distinct osteocyte populations. Bone. 2012;50(5): 1115-1122.

5. Crockett JC, Rogers MJ, Coxon FP, Hocking LJ, Helfrich MH. Bone remodelling at a glance. J Cell Sci. 2011;124(Pt 7):991-998.

6. Kanis JA, McCloskey EV, Johansson H, Oden A, Melton LJ 3rd, Khaltaev N. A reference standard for the description of osteoporosis. Bone. 2008;42(3):467-475.

7. Kanis JA, Johnell O. Requirements for DXA for the management of osteoporosis in Europe. Osteoporos Int. 2005;16(3):229-238.

8. Khosla S, Melton LJ 3rd, Riggs BL. The unitary model for estrogen deficiency and the pathogenesis of osteoporosis: is a revision needed? J Bone Miner Res. 2011;26(3):441-451.

9. Hughes DE, Dai A, Tiffee JC, Li HH, Mundy GR, Boyce BF. Estrogen promotes apoptosis of murine osteoclasts mediated by TGF-beta. Nat Med. 1996;2(10):1132-1136. 
10. Kawano H, Sato T, Yamada T, et al. Suppressive function of androgen receptor in bone resorption. Proc Natl Acad Sci U S A. 2003; 100(16):9416-9421.

11. Sinnesael M, Boonen S, Claessens F, Gielen E, Vanderschueren D. Testosterone and the male skeleton: a dual mode of action. J Osteoporos. 2011;2011:240328.

12. Walker-Bone K. Recognizing and treating secondary osteoporosis. Nat Rev Rheumatol. 2012;8(8):480-492.

13. Yadav VK, Oury F, Suda N, et al. A serotonin-dependent mechanism explains the leptin regulation of bone mass, appetite, and energy expenditure. Cell. 2009;138(5):976-989.

14. Rizzoli R, Cooper C, Reginster JY, et al. Antidepressant medications and osteoporosis. Bone. 2012;51(3):606-613.

15. Pasco JA, Seeman E, Henry MJ, Merriman EN, Nicholson GC, Kotowicz MA. The population burden of fractures originates in women with osteopenia, not osteoporosis. Osteoporos Int. 2006;17(9): 1404-1409.

16. Lems WF, Raterman HG, van den Bergh JP, et al. Osteopenia: a diagnostic and therapeutic challenge. Curr Osteoporos Rep. 2011;9(3):167-172.

17. US Preventive Services Task Force. Screening for osteoporosis: recommendation statement. Am Fam Physician. 2011;83(10): 1197-1200.

18. Nishiyama KK, Macdonald HM, Hanley DA, Boyd SK. Women with previous fragility fractures can be classified based on bone microarchitecture and finite element analysis measured with HR-pQCT. Osteoporos Int. 2013;24(5):1733-1740.

19. Kanis JA, Oden A, Johansson H, Borgstrom F, Strom O, McCloskey E. FRAX and its applications to clinical practice. Bone. 2009;44(5) 734-743.

20. Hippisley-Cox J, Coupland C. Derivation and validation of updated QFracture algorithm to predict risk of osteoporotic fracture in primary care in the united kingdom: prospective open cohort study. BMJ. 2012;344:e3427.

21. Nguyen ND, Frost SA, Center JR, Eisman JA, Nguyen TV. Development of prognostic nomograms for individualizing 5-year and 10-year fracture risks. Osteoporos Int. 2008;19(10):1431-1444.

22. Bolland MJ, Siu AT, Mason BH, et al. Evaluation of the FRAX and garvan fracture risk calculators in older women. $J$ Bone Miner Res. 2011;26(2):420-427.

23. Bolland MJ, Jackson R, Gamble GD, Grey A. Discrepancies in predicted fracture risk in elderly people. BMJ. 2013;346:e8669.

24. Kanis JA, Oden A, Johansson H, McCloskey E. Pitfalls in the external validation of FRAX. Osteoporos Int. 2012;23(2):423-431.

25. Poku EK, Towler MR, Cummins NM, Newman JD. Developing novel prognostic biomarkers for multivariate fracture risk prediction algorithms. Calcif Tissue Int. 2012;91(3):204-214.

26. Gregory JS, Testi D, Stewart A, Undrill PE, Reid DM, Aspden RM. A method for assessment of the shape of the proximal femur and its relationship to osteoporotic hip fracture. Osteoporos Int. 2004 15(1):5-11.

27. Faulkner KG, Cummings SR, Black D, Palermo L, Gluer CC, Genant HK. Simple measurement of femoral geometry predicts hip fracture: The study of osteoporotic fractures. J Bone Miner Res. 1993 8(10):1211-1217.

28. Fritscher K, Grunerbl A, Hanni M, Suhm N, Hengg C, Schubert R. Trabecular bone analysis in CT and X-ray images of the proximal femur for the assessment of local bone quality. IEEE Trans Med Imaging. 2009;28(10):1560-1575.

29. Goodyear SR, Barr RJ, McCloskey E, et al. Can we improve the prediction of hip fracture by assessing bone structure using shape and appearance modelling? Bone. 2013;53(1):188-193.

30. Whitmarsh T, Fritscher KD, Humbert L, et al. Hip fracture discrimination from dual-energy X-ray absorptiometry by statistical model registration. Bone. 2012;51(5):896-901.

31. Baker-LePain JC, Luker KR, Lynch JA, Parimi N, Nevitt MC, Lane NE. Active shape modeling of the hip in the prediction of incident hip fracture. J Bone Miner Res. 2011;26(3):468-474.
32. Pocock NA, Eisman JA, Hopper JL, Yeates MG, Sambrook PN, Eberl S. Genetic determinants of bone mass in adults. A twin study. J Clin Invest. 1987;80(3):706-710.

33. Gueguen R, Jouanny P, Guillemin F, Kuntz C, Pourel J, Siest G. Segregation analysis and variance components analysis of bone mineral density in healthy families. J Bone Miner Res. 1995; 10(12):2017-2022.

34. Richards JB, Rivadeneira F, Inouye M, et al. Bone mineral density, osteoporosis, and osteoporotic fractures: a genome-wide association study. Lancet. 2008;371(9623):1505-1512.

35. Styrkarsdottir U, Halldorsson BV, Gretarsdottir S, et al. New sequence variants associated with bone mineral density. Nat Genet. 2009; 41(1):15-17.

36. Estrada K, Styrkarsdottir U, Evangelou E, et al. Genome-wide metaanalysis identifies 56 bone mineral density loci and reveals 14 loci associated with risk of fracture. Nat Genet. 2012;44(5):491-501.

37. Ralston SH, Uitterlinden AG. Genetics of osteoporosis. Endocr Rev. 2010;31(5):629-662.

38. Hannan MT, Felson DT, Dawson-Hughes B, et al. Risk factors for longitudinal bone loss in elderly men and women: the Framingham Osteoporosis Study. J Bone Miner Res. 2000;15(4):710-720.

39. Body JJ, Bergmann P, Boonen S, et al. Non-pharmacological management of osteoporosis: a consensus of the Belgian Bone Club. Osteoporos Int. 2011;22(11):2769-2788.

40. Downey PA, Perry SB, Anderson JM. Screening postmenopausal women for fall and fracture prevention. $J$ Geriatr Phys Ther. Epub December 17, 2012.

41. Caroli A, Poli A, Ricotta D, Banfi G, Cocchi D. Invited review: Dairy intake and bone health: a viewpoint from the state of the art. J Dairy Sci. 2011;94(11):5249-5262.

42. Reid DM, Macdonald HM. Nutrition and bone: is there more to it than just calcium and vitamin D? QJM. 2001;94(2):53-56.

43. Nieves JW. Skeletal effects of nutrients and nutraceuticals, beyond calcium and vitamin D. Osteoporos Int. 2013;24(3):771-786.

44. Rogers MJ, Crockett JC, Coxon FP, Monkkonen J. Biochemical and molecular mechanisms of action of bisphosphonates. Bone. 2011; 49(1):34-41

45. Frith JC, Monkkonen J, Auriola S, Monkkonen H, Rogers MJ. The molecular mechanism of action of the antiresorptive and antiinflammatory drug clodronate: evidence for the formation in vivo of a metabolite that inhibits bone resorption and causes osteoclast and macrophage apoptosis. Arthritis Rheum. 2001;44(9):2201-2210.

46. Francis MD, Valent DJ. Historical perspectives on the clinical development of bisphosphonates in the treatment of bone diseases. J Musculoskelet Neuronal Interact. 2007;7(1):2-8.

47. Smith R, Russell RG, Bishop M. Diphosphonates and Page's disease of bone. Lancet. 1971;1(7706):945-947.

48. Watts NB, Harris ST, Genant HK, et al. Intermittent cyclical etidronate treatment of postmenopausal osteoporosis. N Engl J Med. 1990; 323(2):73-79.

49. Luckman SP, Hughes DE, Coxon FP, Graham R, Russell G, Rogers MJ. Nitrogen-containing bisphosphonates inhibit the mevalonate pathway and prevent post-translational prenylation of GTP-binding proteins, including Ras. J Bone Miner Res. 1998;13(4):581-589.

50. Fisher JE, Rogers MJ, Halasy JM, et al. Alendronate mechanism of action: Geranylgeraniol, an intermediate in the mevalonate pathway, prevents inhibition of osteoclast formation, bone resorption, and kinase activation in vitro. Proc Natl Acad Sci U S A. 1999;96(1):133-138.

51. Itzstein C, Coxon FP, Rogers MJ. The regulation of osteoclast function and bone resorption by small GTPases. Small GTPases. 2011;2(3): $117-130$.

52. van Beek E, Pieterman E, Cohen L, Lowik C, Papapoulos S. Nitrogen-containing bisphosphonates inhibit isopentenyl pyrophosphate isomerase/farnesyl pyrophosphate synthase activity with relative potencies corresponding to their antiresorptive potencies in vitro and in vivo. Biochem Biophys Res Commun. 1999;255(2): $491-494$. 
53. Dunford JE, Thompson K, Coxon FP, et al. Structure-activity relationships for inhibition of farnesyl diphosphate synthase in vitro and inhibition of bone resorption in vivo by nitrogen-containing bisphosphonates. J Pharmacol Exp Ther. 2001;296(2):235-242.

54. Black DM, Thompson DE, Bauer DC, et al. Fracture risk reduction with alendronate in women with osteoporosis: The fracture intervention trial. FIT research group. J Clin Endocrinol Metab. 2000; 85(11):4118-4124.

55. Rizzoli R. Zoledronic acid for the treatment and prevention of primary and secondary osteoporosis. Ther Adv Musculoskelet Dis. 2010;2(1):3-16.

56. Welton JL, Morgan MP, Marti S, et al. Monocytes and $\gamma \delta \mathrm{T}$ cells control the acute phase response to intravenous zoledronate: insights from a phase IV safety trial. J Bone Miner Res. 2013;28(3):464-471.

57. Khosla S, Burr D, Cauley J, et al. Bisphosphonate-associated osteonecrosis of the jaw: report of a task force of the American Society for Bone and Mineral Research. J Bone Miner Res. 2007;22(10): 1479-1491.

58. Fleisher KE, Jolly A, Venkata UD, Norman RG, Saxena D, Glickman RS. Osteonecrosis of the jaw onset times are based on the route of bisphosphonate therapy. J Oral Maxillofac Surg. 2013;71(3): 513-519.

59. Assael LA. Oral bisphosphonates as a cause of bisphosphonate-related osteonecrosis of the jaws: Clinical findings, assessment of risks, and preventive strategies. J Oral Maxillofac Surg. 2009;67(Suppl 5):35-43.

60. Shane E, Burr D, Ebeling PR, et al. Atypical subtrochanteric and diaphyseal femoral fractures: report of a task force of the American Society for Bone and Mineral Research. J Bone Miner Res. 2010;25(11): 2267-2294.

61. Marx RE, SawatariY, Fortin M, Broumand V. Bisphosphonate-induced exposed bone (osteonecrosis/osteopetrosis) of the jaws: Risk factors, recognition, prevention, and treatment. J Oral Maxillofac Surg. 2005; 63(11):1567-1575.

62. Thompson RN, Phillips JR, McCauley SH, Elliott JR, Moran CG. Atypical femoral fractures and bisphosphonate treatment: experience in two large United Kingdom teaching hospitals. J Bone Joint Surg Br. 2012;94(3):385-390.

63. Abrahamsen B, Einhorn TA. Beyond a reasonable doubt? Bisphosphonates and atypical femur fractures. Bone. 2012;50(5):1196-1200.

64. Black DM, Delmas PD, Eastell R, et al. Once-yearly zoledronic acid for treatment of postmenopausal osteoporosis. N Engl J Med. 2007; 356(18):1809-1822.

65. Levy ME, Parker RA, Ferrell RE, Zmuda JM, Greenspan SL. Farnesyl diphosphate synthase: a novel genotype association with bone mineral density in elderly women. Maturitas. 2007;57(3):247-252.

66. Marini F, Falchetti A, Silvestri S, et al. Modulatory effect of farnesyl pyrophosphate synthase (FDPS) rs2297480 polymorphism on the response to long-term amino-bisphosphonate treatment in postmenopausal osteoporosis. Curr Med Res Opin. 2008;24(9):2609-2615.

67. Olmos JM, Zarrabeitia MT, Hernandez JL, Sanudo C, Gonzalez-Macias J, Riancho JA. Common allelic variants of the farnesyl diphosphate synthase gene influence the response of osteoporotic women to bisphosphonates. Pharmacogenomics J. 2012;12(3):227-232.

68. Das S, Crockett JC, Rogers MJ. Upregulation of endogenous FPP synthase in cultured cells causes resistance to bisphosphonate. Bone. 2011;48(Suppl 2):S231-S231.

69. Cummings SR, San Martin J, McClung MR, et al. Denosumab for prevention of fractures in postmenopausal women with osteoporosis. N Engl J Med. 2009;361(8):756-765.

70. Seeman E, Delmas PD, Hanley DA, et al. Microarchitectural deterioration of cortical and trabecular bone: Differing effects of denosumab and alendronate. J Bone Miner Res. 2010;25(8):1886-1894.

71. Malan J, Ettinger K, Naumann E, Beirne OR. The relationship of denosumab pharmacology and osteonecrosis of the jaws. Oral Surg Oral Med Oral Pathol Oral Radiol. 2012;114(6):671-676.

72. Davey RA, Findlay DM. Calcitonin: physiology or fantasy? J Bone Miner Res. Epub March 20, 2013.
73. Chambers TJ, Magnus CJ. Calcitonin alters behaviour of isolated osteoclasts. J Pathol. 1982;136(1):27-39.

74. Shlossman M, Brown M, Shapiro E, Dziak R. Calcitonin effects on isolated bone cells. Calcif Tissue Int. 1982;34(2):190-196.

75. Downs RW Jr, Bell NH, Ettinger MP, et al. Comparison of alendronate and intranasal calcitonin for treatment of osteoporosis in postmenopausal women. J Clin Endocrinol Metab. 2000;85(5):1783-1788.

76. European Medicines Agency. Questions and Answers on the Review of Calcitonin Containing Medicines: outcome of a procedure under Article 31 of Directive 2001/83/EC. London, UK: European Medicines Agency; 2012. Available from: http://www.ema.europa.eu/docs/en_GB/ document_library/Referrals_document/Calcitonin_31/WC500134838. pdf. Accessed April 18, 2013.

77. Watson PH, Hanley DA. Parathyroid hormone: Regulation of synthesis and secretion. Clin Invest Med. 1993;16(1):58-77.

78. Reeve J, Meunier PJ, Parsons JA, et al. Anabolic effect of human parathyroid hormone fragment on trabecular bone in involutional osteoporosis: a multicentre trial. Br Med J. 1980;280(6228): $1340-1344$.

79. Reeve J, Arlot M, Price TR, et al. Periodic courses of human 1-34 parathyroid peptide alternating with calcitriol paradoxically reduce bone remodelling in spinal osteoporosis. Eur J Clin Invest. 1987;17(5):421-428.

80. Finkelstein JS, Wyland JJ, Lee H, Neer RM. Effects of teriparatide, alendronate, or both in women with postmenopausal osteoporosis. J Clin Endocrinol Metab. 2010;95(4):1838-1845.

81. Yamamoto T, Tsujimoto M, Hamaya E, Sowa H. Assessing the effect of baseline status of serum bone turnover markers and vitamin $\mathrm{D}$ levels on efficacy of teriparatide $20 \mu \mathrm{g} / \mathrm{day}$ administered subcutaneously in Japanese patients with osteoporosis. J Bone Miner Metab. 2013; 31(2):199-205.

82. Saag KG, Shane E, Boonen S, et al. Teriparatide or alendronate in glucocorticoid-induced osteoporosis. N Engl J Med. 2007;357(20): 2028-2039.

83. Deal C, Omizo M, Schwartz EN, et al. Combination teriparatide and raloxifene therapy for postmenopausal osteoporosis: Results from a 6-month double-blind placebo-controlled trial. J Bone Miner Res. 2005; 20(11):1905-1911.

84. Miller PD, Delmas PD, Lindsay R, et al. Early responsiveness of women with osteoporosis to teriparatide after therapy with alendronate or risedronate. J Clin Endocrinol Metab. 2008;93(10):3785-3793.

85. Jilka RL, Weinstein RS, Bellido T, Roberson P, Parfitt AM, Manolagas SC. Increased bone formation by prevention of osteoblast apoptosis with parathyroid hormone. J Clin Invest. 1999;104(4):439-446.

86. D'Amelio P, Tamone C, Sassi F, et al. Teriparatide increases the maturation of circulating osteoblast precursors. Osteoporos Int. 2012;23(4):1245-1253.

87. Watanabe A, Yoneyama S, Nakajima M, et al. Osteosarcoma in Sprague-Dawley rats after long-term treatment with teriparatide (human parathyroid hormone (1-34)). J Toxicol Sci. 2012;37(3):617-629.

88. Andrews EB, Gilsenan AW, Midkiff K, et al. The US postmarketing surveillance study of adult osteosarcoma and teriparatide: study design and findings from the first 7 years. $J$ Bone Miner Res. 2012;27(12): 2429-2437.

89. Shiraki M, Sugimoto T, Nakamura T. Effects of a single injection of teriparatide on bone turnover markers in postmenopausal women. Osteoporos Int. 2013;24(1):219-226.

90. Devogelaer JP, Boutsen Y, Manicourt DH. Biologicals in osteoporosis: teriparatide and parathyroid hormone in women and men. Curr Osteoporos Rep. 2010;8(3):154-161.

91. Farra R, Sheppard NF Jr, McCabe L, et al. First-in-human testing of a wirelessly controlled drug delivery microchip. Sci Transl Med. 2012; 4(122):122ra21.

92. Boivin G, Deloffre P, Perrat B, et al. Strontium distribution and interactions with bone mineral in monkey iliac bone after strontium salt (S 12911) administration. J Bone Miner Res. 1996;11(9): 1302-1311. 
93. Meunier PJ, Slosman DO, Delmas PD, et al. Strontium ranelate: dose-dependent effects in established postmenopausal vertebral osteoporosis - a 2-year randomized placebo controlled trial. J Clin Endocrinol Metab. 2002;87(5):2060-2066.

94. Meunier PJ, Roux C, Seeman E, et al. The effects of strontium ranelate on the risk of vertebral fracture in women with postmenopausal osteoporosis. N Engl J Med. 2004;350(5):459-468.

95. Reginster JY, Seeman E, De Vernejoul MC, et al. Strontium ranelate reduces the risk of nonvertebral fractures in postmenopausal women with osteoporosis: Treatment of Peripheral Osteoporosis (TROPOS) study. J Clin Endocrinol Metab. 2005;90(5):2816-2822.

96. Bonnelye E, Chabadel A, Saltel F, Jurdic P. Dual effect of strontium ranelate: Stimulation of osteoblast differentiation and inhibition of osteoclast formation and resorption in vitro. Bone. 2008;42(1) $129-138$.

97. Hurtel-Lemaire AS, Mentaverri R, Caudrillier A, et al. The calciumsensing receptor is involved in strontium ranelate-induced osteoclast apoptosis. New insights into the associated signaling pathways. $J$ Biol Chem. 2009;284(1):575-584

98. Fromigue O, Hay E, Barbara A, et al. Calcium sensing receptordependent and receptor-independent activation of osteoblast replication and survival by strontium ranelate. J Cell $\mathrm{Mol} \mathrm{Med}$. 2009;13(8B):2189-2199.

99. Caudrillier A, Hurtel-Lemaire AS, Wattel A, et al. Strontium ranelate decreases receptor activator of nuclear factor- $\kappa \mathrm{B}$ ligand-induced osteoclastic differentiation in vitro: involvement of the calciumsensing receptor. Mol Pharmacol. 2010;78(4):569-576.

100. Caverzasio J. Strontium ranelate promotes osteoblastic cell replication through at least two different mechanisms. Bone. 2008;42(6): 1131-1136.

101. Rizzoli R, Reginster JY. Adverse drug reactions to osteoporosis treatments. Expert Rev Clin Pharmacol. 2011;4(5):593-604.

102. Rossouw JE, Anderson GL, Prentice RL, et al. Risks and benefits of estrogen plus progestin in healthy postmenopausal women: principal results from the women's health initiative randomized controlled trial. JAMA. 2002;288(3):321-333.

103. Breast cancer and hormone replacement therapy: collaborative reanalysis of data from 51 epidemiological studies of 52,705 women with breast cancer and 108,411 women without breast cancer. Collaborative Group on Hormonal Factors in Breast Cancer. Lancet. 1997;350(9084):1047-1059.

104. Delmas PD, Bjarnason NH, Mitlak BH, et al. Effects of raloxifene on bone mineral density, serum cholesterol concentrations, and uterine endometrium in postmenopausal women. N Engl JMed. 1997;337(23): 1641-1647.

105. Recker RR, Kendler D, Recknor CP, et al. Comparative effects of raloxifene and alendronate on fracture outcomes in postmenopausal women with low bone mass. Bone. 2007;40(4):843-851.

106. Foster SA, Shi N, Curkendall S, et al. Fractures in women treated with raloxifene or alendronate: a retrospective database analysis. $B M C$ Womens Health. 2013;13(1):15.

107. Barrett-Connor E, Mosca L, Collins P, Geiger MJ, Grady D, et al; Raloxifene Use for the Heart (RUTH) Trial Investigators. Effects of raloxifene on cardiovascular events and breast cancer in postemenopausal women. $N$ Engl J Med. 2006;355(2):125-137.

108. Lee WL, Chao HT, Cheng MH, Wang PH. Rationale for using raloxifene to prevent both osteoporosis and breast cancer in postmenopausal women. Maturitas. 2008;60(2):92-107.

109. Ming LG, Chen KM, Xian CJ. Functions and action mechanisms of flavonoids genistein and icariin in regulating bone remodeling. $J$ Cell Physiol. 2013;228(3):513-521.

110. Morgan JL, Skulan JL, Gordon GW, Romaniello SJ, Smith SM, Anbar AD. Rapidly assessing changes in bone mineral balance using natural stable calcium isotopes. Proc Natl Acad Sci U S A. 2012; 109(25):9989-9994.

111. Jansen JP, Bergman GJ, Huels J, Olson M. Prevention of vertebral fractures in osteoporosis: Mixed treatment comparison of bisphosphonate therapies. Curr Med Res Opin. 2009;25(8):1861-1868.
112. Freemantle N, Cooper C, Diez-Perez A, et al. Results of indirect and mixed treatment comparison of fracture efficacy for osteoporosis treatments: a meta-analysis. Osteoporos Int. 2013;24(1):209-217.

113. Balemans W, Ebeling M, Patel N, et al. Increased bone density in sclerosteosis is due to the deficiency of a novel secreted protein (SOST). Hum Mol Genet. 2001;10(5):537-543.

114. Lin C, Jiang X, Dai Z, et al. Sclerostin mediates bone response to mechanical unloading through antagonizing Wnt/beta-catenin signaling. J Bone Miner Res. 2009;24(10):1651-1661.

115. Spatz J, Ellman R, Cloutier A, et al. Sclerostin antibody inhibits skeletal deterioration due to reduced mechanical loading. J Bone Miner Res. 2013;28(4):865-874

116. Padhi D, Jang G, Stouch B, Fang L, Posvar E. Single-dose, placebocontrolled, randomized study of AMG 785, a sclerostin monoclonal antibody. J Bone Miner Res. 2011;26(1):19-26.

117. Costa AG, Bilezikian JP. Sclerostin: therapeutic horizons based upon its actions. Curr Osteoporos Rep. 2012;10(1):64-72.

118. Inaoka T, Bilbe G, Ishibashi O, Tezuka K, Kumegawa M, Kokubo T. Molecular cloning of human cDNA for cathepsin K: novel cysteine proteinase predominantly expressed in bone. Biochem Biophys Res Commun. 1995;206(1):89-96.

119. LiYP, Alexander M, Wucherpfennig AL, Yelick P, Chen W, Stashenko P. Cloning and complete coding sequence of a novel human cathepsin expressed in giant cells of osteoclastomas. J Bone Miner Res. 1995 ; 10(8):1197-1202.

120. Gelb BD, Shi GP, Chapman HA, Desnick RJ. Pycnodysostosis, a lysosomal disease caused by cathepsin K deficiency. Science. 1996; 273(5279): $1236-1238$

121. Saftig P, Hunziker E, Wehmeyer O, et al. Impaired osteoclastic bone resorption leads to osteopetrosis in cathepsin-K-deficient mice. Proc Natl Acad Sci U S A. 1998;95(23):13453-13458.

122. Gauthier JY, Chauret N, Cromlish W, et al. The discovery of odanacatib (MK-0822), a selective inhibitor of cathepsin K. Bioorg Med Chem Lett. 2008;18(3):923-928.

123. Perez-Castrillon JL, Pinacho F, De Luis D, Lopez-Menendez M, Duenas Laita A. Odanacatib, a new drug for the treatment of osteoporosis: review of the results in postmenopausal women. $J$ Osteoporos. June 14, 2010;2010. pii: 401581.

124. $\mathrm{Ng} \mathrm{KW}$. Potential role of odanacatib in the treatment of osteoporosis Clin Interv Aging. 2012;7:235-247.

125. Steinert AF, Rackwitz L, Gilbert F, Noth U, Tuan RS. Concise review: the clinical application of mesenchymal stem cells for musculoskeletal regeneration: current status and perspectives. Stem Cells Transl Med. 2012;1(3):237-247.

126. Guan M, Yao W, Liu R, et al. Directing mesenchymal stem cells to bone to augment bone formation and increase bone mass. Nat Med. 2012;18(3):456-462.

127. Watts NB, Adler RA, Bilezikian JP, et al. Osteoporosis in men: an endocrine society clinical practice guideline. J Clin Endocrinol Metab 2012;97(6):1802-1822.

128. Gertz BJ, Holland SD, Kline WF, Matuszewski BK, Porras AG. Clinical pharmacology of alendronate sodium. Osteoporos Int. 1993; 3 Suppl 3:S13-S16.

129. Whitaker M, Guo J, Kehoe T, Benson G. Bisphosphonates for osteoporosis - where do we go from here? NEngl J Med. 2012;366(22): 2048-2051.

130. Watts NB, Diab DL. Long-term use of bisphosphonates in osteoporosis $J$ Clin Endocrinol Metab. 2010;95(4):1555-1565.

131. Chen T, Berenson J, Vescio R, et al. Pharmacokinetics and pharmacodynamics of zoledronic acid in cancer patients with bone metastases. J Clin Pharmacol. 2002;42(11):1228-1236.

132. Romero Barco CM, Manrique Arija S, Rodriguez Perez M. Biochemical markers in osteoporosis: usefulness in clinical practice. Reumatol Clin. 2012;8(3):149-152.

133. Torres E, Mezquita P, DeLa Higuera M, Fernandez D, Munoz M. Actualizacion sobre la determinacion de marcadores de remodelado oseo. [Determination of markers of bone remodeling: an update.] Endocrinol Nutr. 2003;50(6):237-243. Spanish. 


\section{Publish your work in this journal}

Drug Design, Development and Therapy is an international, peerreviewed open-access journal that spans the spectrum of drug design and development through to clinical applications. Clinical outcomes, patient safety, and programs for the development and effective, safe, and sustained use of medicines are a feature of the journal, which

has also been accepted for indexing on PubMed Central. The manuscript management system is completely online and includes a very quick and fair peer-review system, which is all easy to use. Visit http://www.dovepress.com/testimonials.php to read real quotes from published authors.

Submit your manuscript here: http://www.dovepress.com/drug-design-development-and-therapy-journal 